\title{
Quality Profiling at the TCM Hospital Bad Kötzting - Examples from an Ongoing Systematic Patient Documentation
}

\author{
Wolfgang Weidenhammer ${ }^{a}$ Dieter Melcharta ${ }^{a, b}$ \\ ${ }^{a}$ Competence Centre for Complementary Medicine and Naturopathy, Klinikum rechts der Isar, Technische Universität München, Munich, \\ Germany \\ b Institute for Complementary and Integrative Medicine, University Hospital Zurich and University of Zurich, Zurich, Switzerland
}

\section{Keywords}

Traditional Chinese Medicine - Quality profile .

Routine patient documentation · Follow-up · Outcome quality

\section{Summary}

Background: Quality profiling is practiced at the TCM hospital Bad Kötzting since its establishment 25 years ago. The profiling comprises assessment of treatment effectiveness andsafety, structural features, staff qualification as well as diagnostic and therapeutic processes. Findings regarding patients, intervention and outcome profiles are presented by appropriate examples. Methods: Data of each in-patient were systematically collected by physicians and via self-reports at admission, discharge and follow-up. Over the years the system was adjusted several times resulting in a data pool of about 19,000 in-patients by end of 2014. Results: Patients are 52 years old on average, $70 \%$ are female, and suffering from the main complaint since 7 years (median). The diagnostic spectrum changed over the years according to the development towards a psychosomatic focus. For TCM acupuncture therapy 222 different acupoints were used in 7.7 different localisations on average per individual treatment. The mean intensity of the main complaint decreased clinically relevant (Cohen's $d=1.11$ at discharge and 0.93 at follow-up). After the hospital stay the number of days of sick leave declined from 51.3 days by $40 \%$ per patient and year. Depressive disorders as most common mental illness decreased significantly decreased significantly at discharge (ICD symptom rating; Cohen's $d=-1.01$ ). $29.8 \%$ of patients met the criteria for a metabolic syndrome diagnosis according to the International Diabetes Federation (IDF). In this group of cases, triglycerides, cholesterol and blood glucose improved markedly at discharge. Discussion: The presented quality control measures clearly contribute to an enhanced transparency in terms of a comprehensive quality profile. The findings from various outcome parameters indicate that patients benefit from the treatment.

(C) 2016 S. Karger GmbH, Freiburg

\section{Schlüsselwörter}

Traditionelle Chinesische Medizin · Qualitätsprofil .

Patientendokumentation · Nachbefragung · Ergebnisqualität

\section{Zusammenfassung}

Hintergrund: Seit der Gründung vor 25 Jahren werden in der TCM-Klinik Bad Kötzting Qualitätsprofile erhoben. Diese umfassen die Erhebung von Wirksamkeit und Sicherheit der Behandlung, Strukturmerkmalen der Klinik, Mitarbeiterqualifikationen sowie von diagnostischen und therapeutischen Prozessen. Ergebnisse zu Patienten-, Interventions- und Ergebnisprofilen werden anhand geeigneter Beispiele präsentiert. Methoden: Bei Klinikaufnahme, Entlassung und durch Nachbefragungen werden von Arzt und Patient Daten zu allen stationären Patienten erfasst. Das Dokumentationssystem wurde mehrfach angepasst und umfasste bis Ende 2014 etwa 19000 Datensätze. Ergebnisse: Die Patienten sind im Durchschnitt 52 Jahre alt, 70\% sind weiblich. Die Hauptbeschwerde besteht seit 7 Jahren (Median). Das diagnostische Spektrum veränderte sich mit der Entwicklung des psychosomatischen Schwerpunkts der TCM-Klinik hin zu einer Psychosomatischen Fachklinik. Für die TCM-Akupunktur wurden 222 verschiedene Punkte verwendet mit durchschnittlich 7,7 verschiedenen Lokalisationen pro Sitzung. Die mittlere Hauptbeschwerdestärke nahm klinisch bedeutsam ab (Cohens $d=1,11$ bei Entlassung und 0,93 beim Follow-up). Die Anzahl der krankheitsbedingten Fehltage nahm pro Patient und Jahr von 51,3 vor Klinikaufenthalt um $40 \%$ ab (nach Klinikaufenthalt). Depressive Störungen waren als Krankheitsbild am deutlichsten ausgeprägt und reduzierten sich bei Entlassung statistisch signifikant (ICD-Symptomrating; Cohens $d=-1,01$ ). 29,8\% der Patienten erfüllten die IDF-Kriterien (International Diabetes Federation) für das metabolische Syndrom. In dieser Gruppe besserten sich bei Entlassung Triglyceride, Cholesterin und Nüchternzucker deutlich. Diskussion: Die vorgestellten Kontrollmaßnahmen tragen zu einer erhöhten Transparenz im Sinne eines umfassenden Qualitätsprofils bei. Die Ergebnisse mehrerer Parameter deuten darauf hin, dass die Patienten von der Behandlung profitieren.

\section{KARGER \\ Fax +497614520714

() 2016 S. Karger GmbH, Freiburg
$1661-4119 / 16 / 0237-0008 \$ 39.50 / 0$
Wolfgang Weidenhammer, $\mathrm{PhD}$

Competence Centre for Complementary Medicine and Naturopathy

Klinikum rechts der Isar, Technische Universität München

Kaiserstrasse 9, 80801 Munich, Germany

wolfgang.weidenhammer@ tum.de 
Fig. 1. Routine patient documentation at the TCM hospital Bad Kötzting from 1992 to 2014.

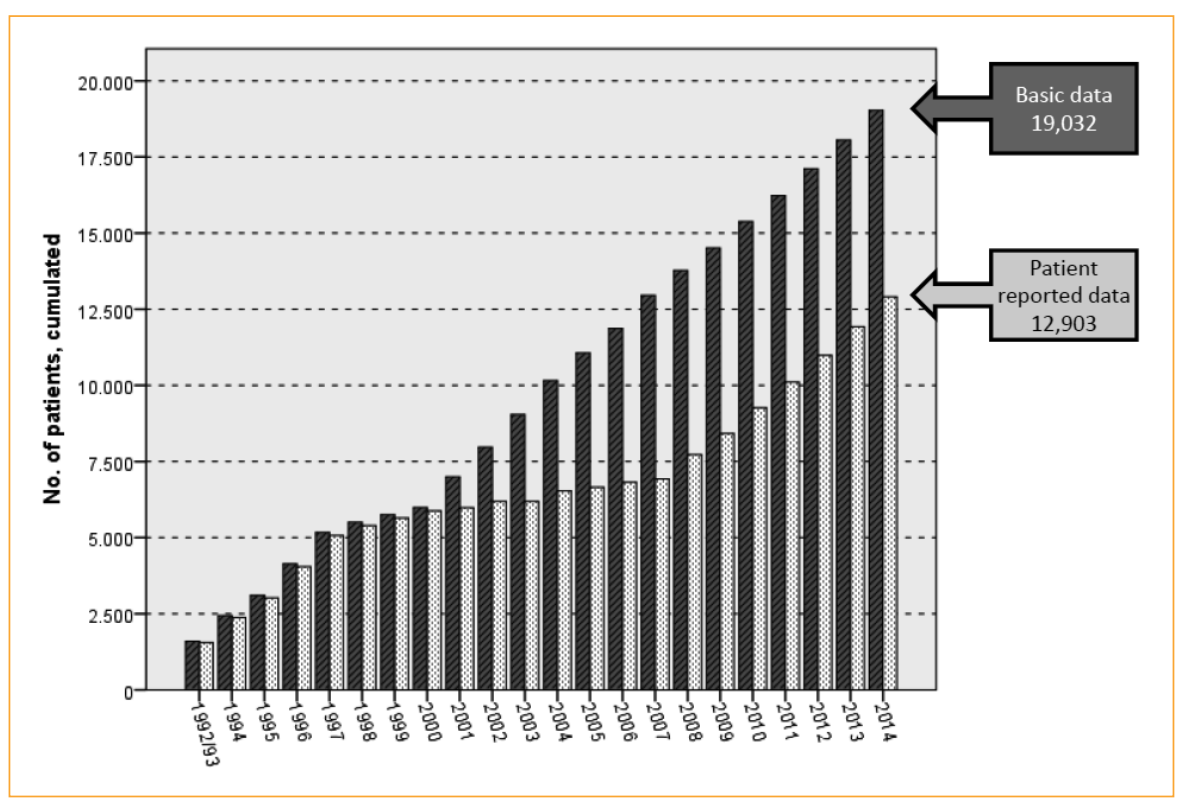

\section{Background}

Providing scientific evidence on a holistic and complex treatment system like Traditional Chinese Medicine (TCM) is a challenging endeavour. The individualised and thus not standardised treatment process does not comply with the claim on a maximum of internal validity in controlled clinical trials. Moreover, TCM drugs often do not fulfil the requirements of medicinal product acts to be approved for drug trials. On the other hand, health care with traditional approaches is practiced by numerous therapists and hospitals. The key question for the patient is therefore how to assure an informed decision based on the quality (including safety of the treatment) and the expected benefit of a particular provider. A scientific quality profiling is an important basis for the authorities and sickness funds and mandatory for the regulations of the German Social Code ( $\$ 137$ SGB V) demanding comparative quality analyses. A comprehensive quality assurance programme was accepted by all statutory sickness funds in 2004, e.g. in the field of rehabilitation medicine [1]. This 'quality profiling' [2-5] goes along with specific methodological considerations [6, 7]. Quality profiling is expected to provide insight into the kind of patients treated, therapeutic methods used and the resulting effects. Further aspects are safety of the applied interventions and structural features of the hospital, such as equipment and personnel qualification, as well as activities to warrant a desired quality of care. Hence, the components of a comprehensive quality profiling [8] address the provider's infrastructure (e.g. number of beds, staff, qualification, medical concept), patients (e.g. age, gender, diagnoses, duration of disease), intervention (TCM drugs, acupuncture points, conventional treatment), outcomes (global intensity of complaint, life satisfaction, mental health, side effects) and aspects of quality assurance (transparency in quality reports, publications). From a medical care perspective, outcome measures are of greater intrinsic interest than process variables [9]. Hence, in this paper we put more emphasis on examples presenting treatment outcome at the TCM hospital Bad Kötzting.

\section{Methods}

Shortly after the formation of the TCM hospital, a first system of patient documentation has been introduced based on paper-and-pencil questionnaires for both physicians and patients to be filled at admission and discharge from hospital, complemented by postal follow-up questionnaires sent out 2, 6 and 12 months after the hospital stay. In addition to basic patient data, the questionnaires covered health-related topics, such as mood, quality of life and global assessments of complaints, and its changes after treatment, thereby being applicable for all patients regardless of their diagnoses. The documentation has been conducted as a routine procedure initially for all patients and not restricted to samples only.

In all the years of practice at the TCM hospital, the process underwent a lot of modifications due to the implementation of different electronic documentation systems and an ongoing development of improved quality indicators. Now, new tools enable the documentation of all constituents of prescribed drug decoctions as well as all acupuncture points being needled in any single treatment session.

Due to these reorganisations of the procedure as well as the conversion to a psychosomatic hospital it was not possible to warrant a gapless data collection for all the years since 1991. The hospital temporarily had to fall back to samples of patients and data collection periods. Nonetheless, by end of 2014 the systematic patient documentation resulted in a data pool of more than 19,000 inpatients nearly 13,000 of which are documented comprehensively by patient-reported data (fig. 1).

In the following results section provides more methodological details in the context of the selected outcome examples.

\section{Results}

\section{Example 1 - Patient Profile}

Table 1 gives a brief overview of patients treated in the TCM hospital during the past years. A basic finding is that age and gender of the patients do not change substantially during the data col- 
Table 1. Basic patient description in four data collection periods

\begin{tabular}{|c|c|c|c|c|}
\hline Data collection period & 1992-1997 & 2001-2004 & $2008-2010$ & 2011-2014 \\
\hline Sample, n (inpatients) & 5,169 & 3,306 & 2,402 & 3,656 \\
\hline Female, \% & 69.3 & 72.7 & 70.0 & 71.2 \\
\hline Age, years (mean \pm standard deviation) & $52.3 \pm 13.8$ & $51.8 \pm 14.1$ & $53.9 \pm 14.8$ & $52.6 \pm 13.5$ \\
\hline Complaints, years (median) & 8.0 & $7.8^{*}$ & 7.4 & 6.9 \\
\hline$>5$ years, $\%$ & 59.7 & 60.9 & 57.8 & 56.4 \\
\hline $\mathrm{A} / \mathrm{B}=$ Certain infectious and parasitic diseases & & 1.0 & 1.1 & 0.2 \\
\hline $\begin{array}{l}\mathrm{C} / \mathrm{D}=\text { Neoplasms; diseases of blood and blood-forming organs and certain } \\
\text { disorders involving the immune mechanism }\end{array}$ & & 0.9 & 1.8 & 0.2 \\
\hline $\mathrm{E}=$ Endocrine, nutritional and metabolic diseases & 5.7 & 0.7 & 1.7 & 0.2 \\
\hline $\mathrm{F}=$ Mental and behavioural disorders & & 1.1 & 16.1 & 92.1 \\
\hline $\mathrm{G}=$ Diseases of the nervous system & 24.1 & 20.0 & 20.3 & 0.9 \\
\hline $\mathrm{H}=$ Diseases of the eye/ear and adnexa & 3.5 & 1.1 & 3.0 & 0.3 \\
\hline $\mathrm{J}=$ Diseases of the respiratory system & 7.3 & 4.2 & 3.5 & 0.3 \\
\hline $\mathrm{K}=$ Diseases of the digestive system & & 7.9 & 6.9 & 0.9 \\
\hline $\mathrm{L}=$ Diseases of the skin and subcutaneous tissue & 2.1 & 3.8 & 2.6 & 0.3 \\
\hline $\mathrm{M}=$ Diseases of the musculoskeletal system and connective tissue & 27.2 & 44.8 & 28.5 & 3.0 \\
\hline $\mathrm{N}=$ Diseases of the genitourinary system & & 0.2 & 1.1 & 0.2 \\
\hline $\begin{array}{l}\mathrm{R}=\text { Symptoms, signs and abnormal clinical and laboratory findings, } \\
\text { not elsewhere classified }\end{array}$ & 11.4 & 11.2 & 9.0 & 0.5 \\
\hline $\mathrm{S} / \mathrm{T}=$ Injury, poisoning and certain other consequences of external causes & & 0.7 & 1.2 & 0.2 \\
\hline $\mathrm{Z}=$ Factors influencing health status and contact with health services & & & 0.4 & 0.1 \\
\hline Other diagnoses & 18.7 & & 0.1 & \\
\hline
\end{tabular}

*Subsample 2003/2004, n = 274 .

**Diagnostic codes from 1992 to 1997 were transferred from ICD-9.

lection periods. Roughly $70 \%$ of the patients are female; age is about 52 years on average. The main complaint persists for a median of about 7 years prior to admission. $60 \%$ of the patients report that they suffer from their condition since more than 5 years. The figures remain nearly unchanged over the whole time period of assessment.

By the year 2000, diagnoses were coded according ICD-9 until the new version ICD-10 was introduced. All diagnoses were documented by the physicians while the disease being the main reason for the inpatient treatment was considered the primary diagnosis. All other concomitant diseases were documented as secondary diagnoses. Table 1 presents an approximate overview of the distribution of the ICD-10-based diagnoses made from 1992 to 2014. By 2010, diseases of the nervous system (chapter G) and diseases of the musculoskeletal system (chapter M) represented the most prominent primary diagnoses. From 2008 to 2010 a shift towards mental and behavioural disorders became evident (chapter F) and even increased with the psychosomatic focus of the hospital. Since then, $92 \%$ of the patients were assigned a primary diagnosis according to the ICD-10 F chapter. The strikingly high percentage of 'other diagnoses' is caused by the conversion from the previous ICD-9 classification. For the majority of patients 3 to 4 secondary diagnoses were documented.

\section{Example 2 - Intervention Profile}

Acupuncture is a main cornerstone of the complex treatment at the TCM hospital Bad Kötzting. For some years now, each acupoint triggered during an acupuncture treatment session is documented by the acupuncturist in the electronic database. The intervention profile is exemplified by acupuncture treatments in 2014: Of 977 patients treated in the hospital, data on acupuncture are available for 845 patients. Each patient received 10.1 acupuncture sessions on average during their hospital stay. Hence, a total of 8,571 treatment sessions with each 7.7 different acupoints on average are captured. The acupuncturists triggered 222 different acupoints complemented by points located outside the meridians but not classified as extra points, e.g., Ashi or trigger points. Based on a total number of about 66,200 documented points, the relative frequencies of the single points are presented in table 2 . The list is limited to those points with an absolute frequency of more than 250. $13.3 \%$ of all points belong to the category of Ashi points followed by 'conception vessel CV1' (6.8\%), 'large intestine LI4' (5.1\%) and 'spleen SP6' (4.5\%).

\section{Example 3 - Outcome Profile (Relief Spending)}

In chronic conditions therapeutic effects have to demonstrate longer lasting benefit beyond short-term effects. The present example shows results from a longitudinal analysis covering the hospital stay and a follow-up survey sent out to the patients about 6 months 
Table 2. Relative frequency of single acupuncture points used in 845 patients from 2014; only points with absolute frequency $>250$ are listed; percentages referred to total number of documented points: 66,206 .

\begin{tabular}{|c|c|c|c|}
\hline \multicolumn{2}{|c|}{ Acupuncture point } & \multirow{2}{*}{$-\mathrm{N}=8,836$} & \multirow{2}{*}{$13.3 \%$} \\
\hline $\begin{array}{l}\text { English, 'other' } \\
\text { points* }\end{array}$ & $\begin{array}{l}\text { German, «eigene» } \\
\text { Punkte }^{\star}\end{array}$ & & \\
\hline CV1 & Kg1 & 4,477 & 6.8 \\
\hline LI4 & Di4 & 3,378 & 5.1 \\
\hline SP6 & MP6 & 2,991 & 4.5 \\
\hline ST25 & Ma25 & 2,814 & 4.3 \\
\hline LV3 & Le3 & 2,196 & 3.3 \\
\hline GB20 & Gb20 & 2,142 & 3.2 \\
\hline GV2 & $\operatorname{Lg} 2$ & 2,107 & 3.2 \\
\hline ST36 & Ma36 & 2,004 & 3.0 \\
\hline KD3 & $\mathrm{Ni3}$ & 1,746 & 2.6 \\
\hline BL25 & $\mathrm{Bl} 25$ & 1,434 & 2.2 \\
\hline BL23 & $\mathrm{Bl} 23$ & 1,235 & 1.9 \\
\hline KD13 & Nil3 & 1,153 & 1.7 \\
\hline LI11 & Dil1 & 1,097 & 1.7 \\
\hline EXB2 & ExB2 & 1,057 & 1.6 \\
\hline SP15 & MP15 & 1,029 & 1.6 \\
\hline GB21 & $\mathrm{Gb} 21$ & 903 & 1.4 \\
\hline KD17 & Nil7 & 813 & 1.2 \\
\hline GB34 & Gb34 & 751 & 1.1 \\
\hline BL11 & Bl11 & 731 & 1.1 \\
\hline TH5 & $3 \mathrm{E} 5$ & 726 & 1.1 \\
\hline HT7 & $\mathrm{Hz} 7$ & 725 & 1.1 \\
\hline BL60 & $\mathrm{Bl} 60$ & 724 & 1.1 \\
\hline LI15 & Di15 & 720 & 1.1 \\
\hline GV1 & Lg1 & 694 & 1.0 \\
\hline BL24 & $\mathrm{Bl} 24$ & 653 & 1.0 \\
\hline KD6 & Ni6 & 632 & 1.0 \\
\hline PC6 & KS6 & 607 & 0.9 \\
\hline BL40 & Bl40 & 597 & 0.9 \\
\hline SP10 & MP10 & 581 & 0.9 \\
\hline EXHN5 & ExHN5 & 571 & 0.9 \\
\hline BL15 & Bl15 & 544 & 0.8 \\
\hline BL54 & $\mathrm{Bl} 54$ & 507 & 0.8 \\
\hline SP9 & MP9 & 487 & 0.7 \\
\hline BL18 & Bl18 & 479 & 0.7 \\
\hline BL26 & $\mathrm{Bl} 26$ & 463 & 0.7 \\
\hline ST35 & Ma35 & 460 & 0.7 \\
\hline GB31 & Gb31 & 457 & 0.7 \\
\hline BL27 & $\mathrm{Bl} 27$ & 456 & 0.7 \\
\hline GB30 & Gb30 & 441 & 0.7 \\
\hline GB39 & Gb39 & 409 & 0.6 \\
\hline ST24 & $\mathrm{Ma} 24$ & 367 & 0.6 \\
\hline LI20 & Di20 & 357 & 0.5 \\
\hline BL17 & Bl17 & 354 & 0.5 \\
\hline BL20 & $\mathrm{Bl} 20$ & 349 & 0.5 \\
\hline GB40 & Gb40 & 314 & 0.5 \\
\hline ST40 & $\mathrm{Ma} 40$ & 312 & 0.5 \\
\hline GB29 & Gb29 & 296 & 0.4 \\
\hline TH17 & $3 \mathrm{E} 17$ & 292 & 0.4 \\
\hline EXLE4 & ExLE4 & 274 & 0.4 \\
\hline LI14 & Dil4 & 259 & 0.4 \\
\hline ST26 & Ma26 & 256 & 0.4 \\
\hline
\end{tabular}

after discharge from the hospital. The results cover the period from 2011 to 2013 and are based on a sample of 2,512 patients. Regardless of their disease, all patients were asked to assess the current intensity of the leading complaint on a 0 (no complaint) to 9 (extremely strong) numeric scale. The response rate for the follow-up questionnaire was 0.70 . By cross-sectional analysis the mean intensities were $6.33(\mathrm{SD}=1.81), 4.17(\mathrm{SD}=2.07)$ and $4.50(\mathrm{SD}=2.26)$ at admission, discharge and follow-up, respectively. The decreases can be expressed as 'effect-sizes' (Cohen's d) of 1.11 and 0.89 at discharge and follow-up, respectively. However, patients who returned the follow-up questionnaire showed higher effects at discharge than those who did not send back the forms. When splitting the total sample into two sub-groups (follow-up participants vs. non-participants) substantial differences with respect to relief spending during the hospital stay occur (fig. 2). A linear regression analysis using the follow-up data was performed to estimate the follow-up value based on the intensity score at discharge from the hospital. After the regression equation $\left(y=2.59+0.468^{*} \mathrm{x} ; \mathrm{y}=\right.$ prediction of follow-up value, $\mathrm{x}=$ value at discharge) to patients with missing data at follow-up, the line graph of the mean intensity values was slightly modified (fig. 2). The modified Cohen's $d$ at follow-up was 0.93 .

At discharge from hospital, $65.4 \%$ of the patients responding to the follow-up questionnaire assessed globally the success of the treatment as 'very good' or 'good', $30.5 \%$ as 'moderate' and $4.1 \%$ as absent ('no success'). The corresponding figures for those who did not return the questionnaire were $49.8 \%, 39.9 \%$ and $10.3 \%$, respectively. Regarding the therapeutic effect at follow-up, $58.5 \%$ of the respondents provided a positive (very good or good) and $41.5 \%$ a less positive (32.2\% moderate, 9.3\% no success) appraisal.

The 'indirect' measurement of changes (difference in two consecutive measurements of complaint intensity) is showing a linear relationship to the 'direct' approach in terms of global assessment of the therapeutic effect. Patients who report a 'very good' success present a mean decrease of 3.7 score points at discharge while a 'good' success is associated with a decrease of 2.6 points. For 'moderate' and 'no' success the mean decreases were 1.2 and 0.3 , respectively (fig. 3).

\section{Example 4 - Outcome Profile (Sick Leave)}

For health economic analyses it is essential to provide data on treatment effects with impact on direct and indirect costs. The following example refers to the change in sick leave before and after treatment at the TCM hospital exemplified in 791 patients up from 2013. At admission to the hospital employed patients were asked about their sick leave during the last 12 months and for how many days, respectively. In the context of the follow-up survey this question was posed again, referring to the period since discharge (means about 7-8 months).

Table 3 shows that $62 \%$ of the patients were employed and thus provided data on their sick leave. While $78.2 \%$ of these patients reported sick leave (median number 28.4 days) for the 12 months prior to admission to the hospital, the rate decreased to $45.2 \%$ at follow-up (median number 12.2 days). However, the follow-up fig- 


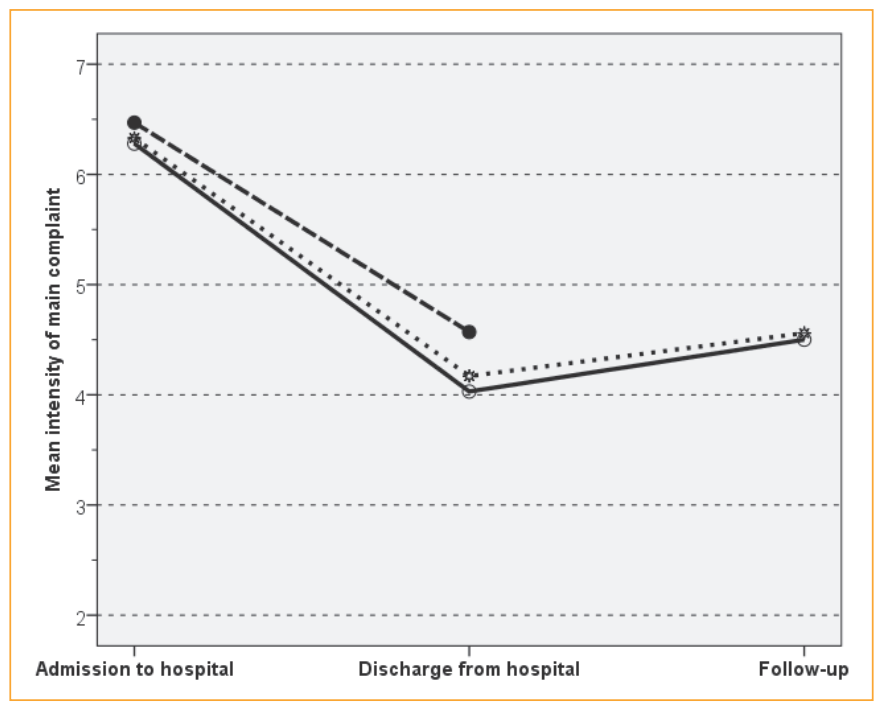

Fig. 2. Patient-reported mean intensity of main complaint on a $0-9$ numeric scale at admission, discharge and follow-up (roughly 7 months after discharge) in two sub-groups (solid line: follow-up participants; dashed line: follow-up non-participants); the dotted line represents the mean values for the total group with missing data at follow-up replaced by a regression-based estimate. Data of 2,512 patients from 2011 to 2013 .

ures had to be adjusted to a comparable time period of 12 months underlying a proportional increase from 7.5 to 12 months. After this correction one has to estimate a percentage of 72.5 for patients with sick leave after the hospital stay. However, the mean number of sick leave days declined from 51.3 to 30.8 days which means a $40 \%$ reduction.

\section{Example 5 - Outcome Profile (Psychopathological Symptomatology)}

In 2010 the patient documentation system has been supplemented with an approved questionnaire on psychopathological syndromes to meet the recently developed psychosomatic focus of the hospital. The ICD symptom rating scale (ISR) [10] is a 29-item questionnaire filled out by the patients. It consists of 5 subscales, i.e. (depressive syndrome, anxiety syndrome, compulsive-obsessive disorder, somatoform disorder, eating disorder) and 12 supplementary items. All items are summed up in a total score. All patients were asked to fill out the questionnaire at admission and discharge from the hospital. This example refers to patients from 2013 focusing on the pre-post changes in depressive syndrome.

Depressive syndrome is the leading syndrome patients suffer from before treatment at the TCM hospital Bad Kötzting. In all these patients, the mean score of depressive syndrome decreases significantly from $1.90(\mathrm{SD}=0.95)$ at admission to $1.02(\mathrm{SD}=0.76)$ at discharge (Cohen's $\mathrm{d}=-1.01$ ) on a scale from 0 to 4 . According to the primary diagnostic subgroup there were differences in both values at admission and discharge (fig. 4). The highest level was found in patients with depressive episodes (F32/33), followed by 'other' F-diagnoses, somatoform pain disorders (F45.4) and patients from group F54. The mean changes after treatment in terms

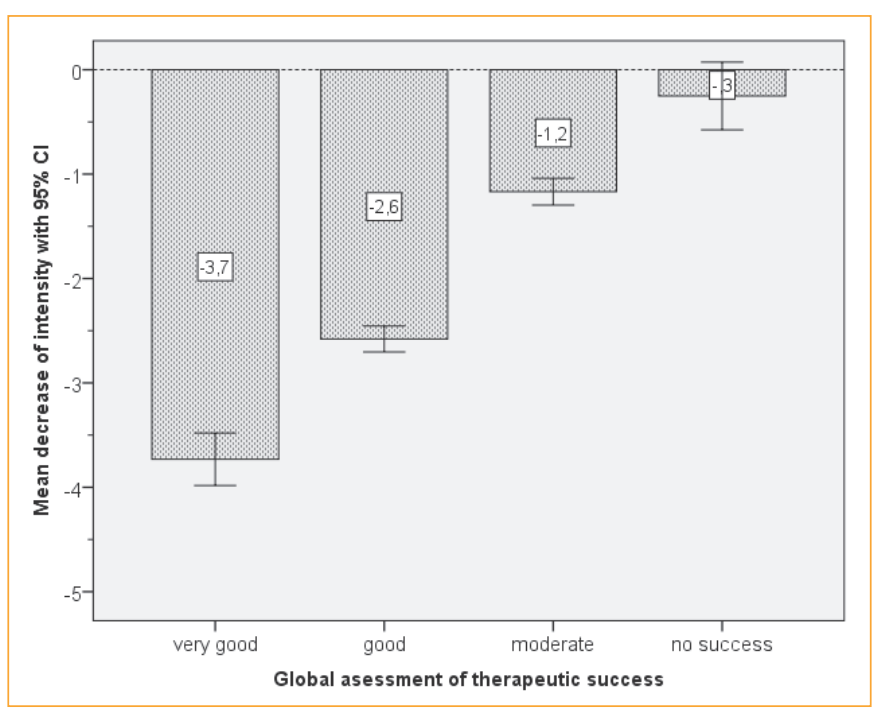

Fig. 3. Mean decrease in intensity of main complaint at discharge from hospital in relation to the global assessment of therapeutic success; data of 2,235 patients from 2011 to 2013.

of Cohen's d were $-1.22,-1.13,-0.86$ and -1.13 , respectively. In general, patients with higher symptom load at admission presented considerably improved health parameters after treatment.

\section{Example 6 - Outcome Profile (Subgroup Analysis in Patients} with Metabolic Syndrome)

The comprehensive data collection allows a subgroup analysis of patients with respect to certain diagnostic or risk groups. This last example is referring to patients from 2009 fulfilling the criteria of a metabolic syndrome (MetS) according to the criteria of the International Diabetes Federation [11]. This retrospective analysis is independent from the clinical diagnoses and the presenting problems being subject of the treatment at that time.

We analysed data of 206 (29.8\%) patients with MetS out of a total of 691 patients. These patients were older $(42.2 \%>60$ years $)$ and more frequently men (36.4\%) compared to those without MetS $(21.9 \%>60$ years, $23.9 \%$ male). Triglycerides, cholesterol and blood glucose are relevant laboratory parameters in patients with MetS and it could be shown that fasting glucose decreased statistically significant in both men and women at discharge from hospital (table 4). A by-product of this analysis is that in men the mean values of liver enzymes also diminished significantly during TCM treatment.

\section{Discussion}

The given examples only represent a small out-take of all findings which could be derived from the available datasets of the TCM hospital Bad Kötzting over the years. The results were described 
Table 3. Pre-post comparison of sick leave (patient-reported) in 791 patients from 2013

\begin{tabular}{|c|c|c|c|c|c|}
\hline Question & Employed & $\begin{array}{l}\text { Sick leave } \\
\text { rate }\end{array}$ & $\begin{array}{l}\text { days, } \mathrm{n} \\
\text { (median) }\end{array}$ & days, $\mathrm{N}$ & $\begin{array}{l}\text { Days per } \\
\text { employed } \\
\text { patient, } \mathrm{n}\end{array}$ \\
\hline $\begin{array}{l}\text { Admission } \\
\text { 'Did you ever stay away from work due to sickness during the past } \\
12 \text { months?' }(\mathrm{N}=791)\end{array}$ & $492(62.2 \%)$ & $385(78.2 \%)$ & 28.4 & 25,229 & 51.3 \\
\hline $\begin{array}{l}\text { Follow-up } \\
\text { 'Did you ever stay away from work due to sickness since discharge } \\
\text { from TCM hospital?' }(\mathrm{N}=542)\end{array}$ & $334(61.6 \%)$ & $\begin{array}{l}151(45.2 \%) \\
242^{*}(72.5 \%)\end{array}$ & 12.2 & $\begin{array}{c}6,439 \\
10,302^{*}\end{array}$ & $\begin{array}{l}19.3 \\
30.8^{\star}\end{array}$ \\
\hline
\end{tabular}

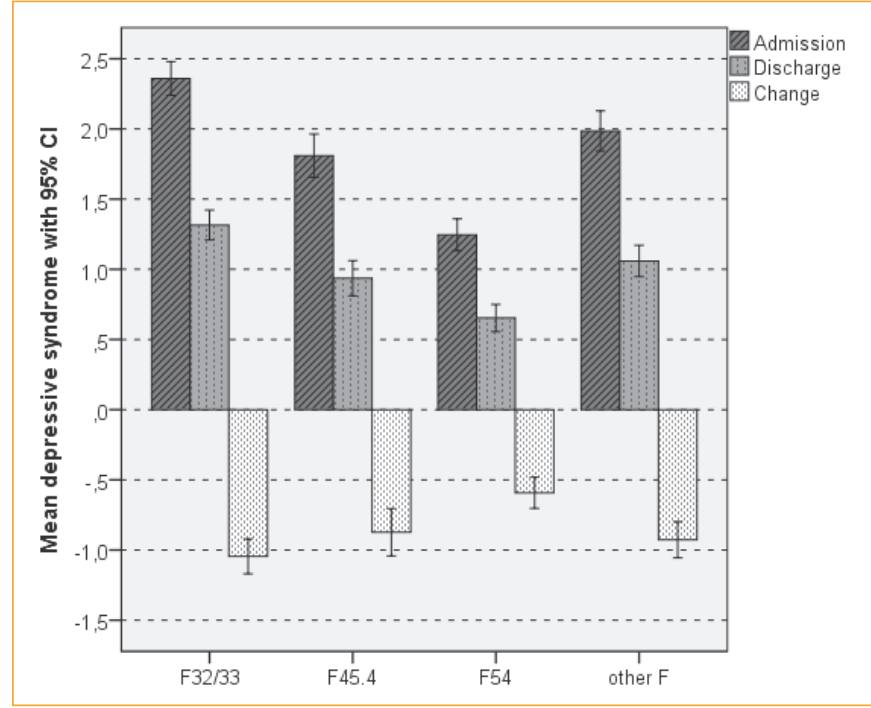

Fig. 4. Psychopathological findings in 664 inpatients of TCM hospital from 2013. Mean values of subscore 'depressive syndrome' (ICD symptom rating, ISR) at admission discharge and pre-post changes in four diagnostic subgroups; F32/33: depressive episodes $(n=223)$; F45.4: somatoform pain disorders $(n=$ 118); F54: Psychological and behavioural factors associated with disorders or diseases classified elsewhere $(n=163)$; other F: other mental and behavioural disorders $(n=160)$.

systematically in a series of internal annual reports but also published in scientific journals serving as components of the hospital's quality assurance profile. Some articles addressed the conceptual basics of quality assurance in complementary medicine in general [12-15] and specifically in TCM $[16,17]$. Methodological challenges of this approach were discussed [18] and comparative prospective studies of TCM versus waiting list or other CAM inpatient facilities were performed $[19,20]$. Some papers focussed on TCM drug treatment with respect to drug quality, compliance and safety [21-26], others investigated psychological factors associated with TCM [27-29]. A recent comprehensive summary of findings of the TCM hospital has been published in a book in 2011 [30].

While acupuncture data collection and outcome measurement is common [e.g. 31], there are only few examples in the literature following the concept of quality profiling of providers of TCM treatment in general. A prospective data collection project was de- veloped and implemented in an outpatient clinic in the USA using self-report questionnaires before admission and one month after discharge [32]. For inpatient TCM treatment there is another example from a German TCM hospital practicing a systematic patient documentation to evaluate outcome quality [33].

The presented findings from the TCM hospital Bad Kötzting clearly contribute to an enhanced transparency regarding who is treated how with which outcomes. Patients are 52 years old on average and about $71 \%$ are female. It is striking that these figures are almost stable over all the years. Half of the patients suffer from their main complaint for about 7.5 years and more. The transition to the status of a psychosomatic hospital is mirrored by the marked changes in the distribution of the primary diagnoses. However, due to the multimorbidity of the patients this is mainly just a shift from primary to secondary diagnoses and vice versa. While some years ago patients were mainly diagnosed with somatic diseases and concomitant mental problems the latter is currently considered the main health problem, in combination with somatic diseases.

In general, it is to appreciate that the TCM hospital is providing a documentation tool for therapeutic interventions on a routine basis. In case of the complex TCM treatment this approach is methodologically challenging. The individualised prescriptions may change according to the clinical course of the patient and are based on the tenets of TCM. Not surprisingly, acupuncture points located at painful spots were frequently used with respect to the high number of pain disorders. However, frequencies of use of single acupuncture points are less meaningful than combinations of multiple points. The identification of such patterns is complex, and for TCM drugs we conducted first empirical analyses to make some progress in this regard [34]. Nonetheless, systematic and electronically available documentation of use of acupuncture points or TCM drugs is a precondition for the investigation of their effectiveness and safety [35]. Moreover, it leads to more transparency and finally, it serves legal requests.

Although the response rate for the follow-up questionnaire of $70 \%$ was fairly good and similar to other experiences in the literature [36] attrition bias always hampers the interpretation of longitudinal data. Last-value-carried-forward is inappropriate for the present situation and would lead to falsely better follow-up values for the intensity of complaints. On the other side, replacement by 
Table 4. Laboratory findings at admission and discharge in patients with metabolic syndrome from 2009

\begin{tabular}{|c|c|c|c|c|}
\hline \multirow[b]{2}{*}{ Laboratory parameter } & \multicolumn{2}{|c|}{ Male $(n=62-65)$} & \multicolumn{2}{|c|}{ Female $(n=113-117)$} \\
\hline & M & $\mathrm{SD}$ & M & $\mathrm{SD}$ \\
\hline \multicolumn{5}{|l|}{ ASAT (U/l) } \\
\hline Admission & 31.3 & 12.7 & 25.1 & 12.2 \\
\hline Discharge & $27.4^{\star * *}$ & 11.4 & $23.1^{*}$ & 9.5 \\
\hline \multicolumn{5}{|l|}{$\operatorname{ALAT}(\mathrm{U} / \mathrm{l})$} \\
\hline Admission & 43.0 & 23.1 & 27.9 & 16.6 \\
\hline Discharge & 40.9 & 23.7 & 27.8 & 19.2 \\
\hline \multicolumn{5}{|l|}{ Gamma-GT (U/l) } \\
\hline Admission & 65.8 & 71.6 & 47.5 & 83.3 \\
\hline Discharge & $50.8^{*}$ & 84.3 & 34.3 & 31.6 \\
\hline \multicolumn{5}{|l|}{ Fasting glucose $(\mathrm{mg} / \mathrm{dl})$} \\
\hline Admision & 114.4 & 22.6 & 112.1 & 28.6 \\
\hline Discharge & $105.3^{* * *}$ & 18.8 & $102.2^{* * *}$ & 19.0 \\
\hline \multicolumn{5}{|l|}{ Total cholesterol (mg/dl) } \\
\hline Admission & 229.8 & 42.0 & 242.4 & 46.9 \\
\hline Discharge & $211.4^{* * *}$ & 39.3 & 237.0 & 44.0 \\
\hline \multicolumn{5}{|l|}{ HDL cholesterol (mg/dl) } \\
\hline Admission & 46.2 & 12.2 & 58.8 & 14.1 \\
\hline Discharge & $42.5^{\star * *}$ & 8.4 & $53.4^{* * *}$ & 11.1 \\
\hline \multicolumn{5}{|l|}{ LDL cholesterol (mg/dl) } \\
\hline Admission & 138.1 & 27.7 & 140.0 & 31.1 \\
\hline Discharge & $128.8^{\star *}$ & 27.0 & 141.3 & 30.1 \\
\hline \multicolumn{5}{|l|}{ Triglycerides (mg/dl) } \\
\hline Admission & 215.7 & 94.4 & 184.9 & 110.7 \\
\hline Discharge & $190.3^{*}$ & 89.6 & 176.9 & 73.2 \\
\hline $\begin{array}{l}\text { ASAT }=\text { aspartate amin } \\
\text { glutamyltransferase. } \\
\mathrm{M}=\text { arithmetic mean; } \mathrm{S} \\
{ }^{*} \mathrm{p}<0.05 . \\
{ }^{* *} \mathrm{p}<0.01 . \\
{ }^{* * *} \mathrm{p}<0.001 .\end{array}$ & $\begin{array}{l}\text { ALAT = } \\
\text { rd deviatio }\end{array}$ & inotrar & ; Gamma- & \\
\hline
\end{tabular}

the baseline value before treatment would cause an excessive and unrealistic deterioration at follow-up. Hence, we preferred a regression-based estimate resulting in a just slightly modified course of means. Yet, the question still remains why patients did not respond to the follow-up questionnaire. Was it ; 1) because they felt particularly bad, 2) they did not feel addressed due to their good health condition, or 3) simply by chance? Irrespective of the question how to deal best with the missing follow-up data, the amount of relief spending is clinically relevant on average, both at discharge from hospital and 6-8 months later. This is also confirmed by the patients' assessment of a 'good' therapeutic success associated with the mean decrease of intensity of complaint by about 2 units on a 0-9 numeric scale.

The analysis of pre-post changes in sick leave has to be interpreted with caution since only patient-reported data are available. The patients of the TCM hospital did not show any significant decrease of sick leave patients rate in patients after treatment as it could be demonstrated elsewhere [37]. However, sick leave days could be reduced to a clinically and economically relevant amount.

The presented results from 2013 indicate a marked improvement at discharge from hospital in terms of the ISR score for de- pressive syndrome, comparable to the findings from other psychosomatic hospitals [38]. The magnitude of benefit is both associated with the primary diagnose and the level of symptom load before treatment. By providing a syndrome profile as well as a total score the ISR questionnaire allows a differentiated analysis of the prepost changes dependent from the specific diagnostic ICD-10 category of mental and behavioural disorders (chapter F).

The subsample analysis of patients with MetS demonstrates the potential of the systematic data collection for optional ex-postfacto analyses. Big samples allow the separation of the patients by one or more stratifying variables resulting in sufficiently high sample sizes in the subgroups. Although MetS was not the primary reason for the inpatient stay, the presented positive laboratory findings in these patients point to the success of a more comprehensive and health-oriented treatment concept [39]. Components of an Individual Health Management [40] have recently been introduced to the treatment concept of the TCM hospital Bad Kötzting and come more and more into effect. In parallel, appropriate quality indicators, such as life satisfaction, health competence, diet and exercise habits have been added to the documentation system which will expand the scope of analyses in future. 


\section{Acknowledgements}

Our special thanks go to the staff of the TCM hospital Bad Kötzting for their strenuous support of the documentation system all over the years, and last but not least to all the patients for filling out the questionnaires and thereby contributing to the description of the hospital's quality of care.

\section{Disclosure Statement}

DM is chair of the hospital's scientific advisory board, WW is member of this board

\section{References}

1 Farin E, Follert P, Gerdes N, Jäckel WH, Thalau J: Quality assessment in rehabilitation centres: the indicator system 'Quality Profile'. Disabil Rehabil 2004;26: 1096-1104.

2 Tucker JL: The theory and methodology of provider profiling. Int J Health Care Qual Assur Inc Leadersh Health Serv 2000;13:316-321.

3 Krein SL, Hofer TP, Kerr EA, Hayward RA: Whom should we profile? Examining diabetes care practice variation among primary care providers, provider groups, and health care facilities. Health Serv Res 2002; 37:1159-1180.

4 Mukamel DB, Zwanziger J, Bamezai A: Hospital competition, resource allocation and quality of care. BMC Health Serv Res 2002;2:10.

5 Farin E, Gerdes N, Jäckel WH, Follert P, Klein K, Glattacker M: 'Quality profiles' of rehabilitation centres: a model of quality assessment in health care institutions (in German). Gesundh ökon Qual manag 2003;8:191204.

6 Normand SL, Glickman ME, Gatsonis CA: Statistical methods for profiling providers of medical care: issues and applications. J Am Stat Assoc 1997;92:803-814.

7 DeLong ER, Peterson ED, DeLong DM, Muhlbaier LH, Hackett S, Mark DB: Comparing risk-adjustment methods for provider profiling. Stat Med 1997;16:26452664.

8 Melchart D, Weidenhammer W, Linde K, Saller R: 'Quality profiling' for complementary medicine: the example of a hospital for traditional Chinese medicine. J Altern Complement Med 2003;9:193-206.

9 Mant J: Process versus outcome indicators in the assessment of quality of health care. Int J Qual Health Care 2001;13:475-480.

10 Tritt K, von Heymann F, Zaudig M, Zacharias I, Sollner W, Loew T: Entwicklung des Fragebogens 'ICD10-Symptom-Rating' (ISR). Z Psychosom Med 2008;54: 425-434.

11 Alberti KG, Zimmet P, Shaw J: Metabolic syndrome - a new world-wide definition. A Consensus Statement from the International Diabetes Federation. Diabet Med 2006:23:469-480.

12 Melchart D, Linde K, Miller R, Polonius D: Qualitätssicherungsvorhaben «Naturheilverfahren» im Rahmen des Klinikverbundes «Münchener Modell». Forsch Komplementmed 1994;1:128-137.

13 Melchart D, Weidenhammer W, Linde K: Scientific quality management in a network of clinics using complementary medicine. Complement Ther Med 1996;4: 163-168.

14 Melchart D, Weidenhammer W, Linde K: Scientific quality management in the network of hospitals of the Münchener Modell. Forschende Komplementmed 1997;4:120-121.
15 Melchart D, Linde K, Liao JZ, Hager S, Weidenhammer $\mathrm{W}$ : Systematic clinical auditing in complementary medicine: rationale, concept, and a pilot study. Altern Ther Health Med 1997;3:33-39.

16 Melchart D, Hager S, Liao JZ, Linde K, Weidenhammer W: Beobachtungsstudien im Rahmen eines naturheilkundlichen Klinikverbunds. Teil II: Detaillierte Ergebnisse der Klinik für Traditionelle Chinesische Medizin Kötzting. Forsch Komplementmed 1998;5: 81-86.

17 Melchart D, Wagner H, Hager S, Saller R, Ernst E: Quality assurance and evaluation of Chinese medicine in Germany. Altern Ther Health Med 2001;7:24.

18 Melchart D, Weidenhammer W, Linde K: Beobachtungsstudien im Rahmen eines naturheilkundlichen Klinikverbunds. Teil IV: Methodische Aspekte, Diskussion und Empfehlungen. Forsch Komplementmed 1998; 5:184-189.

19 Melchart D, Hager S, Hager U, Liao J, Weidenhammer W, Linde K: Treatment of patients with chronic headaches in a hospital for traditional Chinese medicine in Germany. A randomised, waiting list controlled trial. Complement Ther Med 2004;12:71-78.

20 Melchart D, Wessel A, Brand R, Hager S, Weidenhammer W: Profiling quality of care for patients with chronic headache in three different German hospitals - a case study. BMC Health Serv Res 2008;8:13.

21 Melchart D, Linde K, Liao X, Hager S: Herbal treatment in a hospital for traditional Chinese medicine in Germany. Phytomedicine 1996;3(suppl 1):SL-128.

22 Söllner C, Melchart D, Liao X, Hager S: Risk monitoring in a hospital for traditional Chinese medicine in Germany. Phytomedicine 1996;3(suppl 1):SL-129.

23 Melchart D, Linde K, Weidenhammer W, Hager S, Liao JZ, Bauer R, Wagner H: Use of traditional drugs in a hospital of Chinese medicine in Germany. Pharmacoepidemiol Drug Saf 1999;8:115-120.

24 Melchart D, Hager S, Weidenhammer W, Liao JZ, Söllner C, Linde K: Tolerance of and compliance with traditional drug therapy among patients in a hospital for Chinese medicine in Germany. Int J Risk Saf Med 1998; 11:61-64.

25 Melchart D, Linde K, Hager S, Kaesmayr J, Shaw D, Bauer R, Weidenhammer W: Monitoring of liver enzymes in patients treated with traditional Chinese drugs. Complement Ther Med 1999;7:208-216.

26 Melchart D, Weidenhammer W, Hager S, Shaw D, Bauer R: Liver enzyme elevations in patients treated with traditional Chinese medicine. JAMA 1999;282: 28-29.

27 Weidenhammer W, Melchart D, Hager S: Treating chronically ill patients with traditional Chinese medicine - its effects on their quality of life. Qual Life Res 1997;6:741.

28 Weidenhammer W, Melchart D, Hager S: Stabilität der Erfassung von Lebensqualität im Vorfeld einer stationären Einweisung bei Patienten mit chronischen Erkrankungen. Z Med Psychol 1998;7:68-74.
29 Mitzdorf U, Beck K, Horton-Hausknecht J, Weidenhammer W, Kindermann A, Takács M, Astor G, Melchart D: Why do patients seek treatment in hospitals of complementary medicine? J Altern Complement Med 1999;5:463-473.

30 Melchart D, Staudinger A (eds): TCM-Klinik Bad Kötzting - 20 Jahre wissenschaftliche Evaluation der Traditionellen Chinesischen Medizin, Klinikbericht 2011. Bad Kötzting, Systemische Medizin, 2011.

31 Marx BL, Rubin LH, Milley R, Hammerschlag R, Ackerman DL: A prospective patient-centered data collection program at an acupuncture and oriental medicine teaching clinic. J Altern Complement Med 2013;19: 410-415.

32 Maiers M, McKenzie E, Evans R, McKenzie M: The development of a prospective data collection process in a traditional Chinese medicine teaching clinic. J Altern Complement Med 2009;15:305-320.

33 Schmincke C, Torres-Londoño P, Seiling M, Gaus W: Evaluating traditional Chinese medicine provided by the 'Klinik am Steigerwald'. Part 1: methods of assessment. Forsch Komplementmed 2008;15:89-95.

34 Weidenhammer W, Dai J, Melchart D: Use of Chinese drugs in patients with metabolic syndrome in a German TCM hospital. Acupuncture Electro 2014;39:393 (abstract).

35 Melchart D, Hager S, Dai J, Weidenhammer W: Quality control and complication screening programme of Chinese medicinal drugs at the first German hospital of traditional Chinese medicine - a retrospective analysis. Forsch Komplementmed 2016;23(suppl 2):21-28.

36 Semrau J, Hentschke C, Buchmann J, Meng K, Vogel $\mathrm{H}$, Faller H, Bork H, Pfeifer K: Long-term effects of interprofessional biopsychosocial rehabilitation for adults with chronic non-specific low back pain: a multicentre, quasi-experimental study. PLoS One 2015;13: e0118609.

37 Storrø S, Moen J, Svebak S: Effects on sick-leave of a multidisciplinary rehabilitation programme for chronic low back, neck or shoulder pain: comparison with usual treatment. J Rehabil Med 2004;36:12-16.

38 Probst T, Mühlberger A: Änderungssensitivität des ICD-10-Symptom-Ratings. Abstractbuch Deutscher Kongress für Psychosomatische Medizin und Psychotherapie. Berlin, 25.-28.03.2015.

39 Hager S, Dai J, Fischer V, et al.: East meets west: synergy through diversity. Forsch Komplementmed 2016; 23(suppl 2):3-7.

40 Melchart D, Eustachi A, Wellenhofer-Li Y, Bohnes E, Doerfler W: Individual Health Management - a comprehensive lifestyle counselling programme for health promotion, disease prevention and patient education. Forsch Komplementmed 2016;23:30-35. 